\title{
RESISTÊNCIA QUEER: MARCAÇÃO DO TERRITÓRIO GAY NO CENÁRIO HETERONORMATIVO DO ESPORTE ${ }^{46}$
}

\author{
Paula Nunes Chaves \\ Universidade Federal do Rio Grande Norte, Natal, Rio Grande do Norte, Brasil. \\ Allyson Carvalho de Araújo \\ Universidade Federal do Rio Grande Norte, Natal, Rio Grande do Norte, Brasil.
}

\begin{abstract}
Resumo:Este estudo tem como objetivo refletir sobre a prática esportiva dos atletas queer e suas implicações para a conjuntura esportiva moderna, bem como para a Educação Física. Para tanto foram analisados dois filmes: Summer Storm (2004) e Guys and Balls (2004) que nos colocam em contato com esse universo queer no esporte. A partir da apreciação das produções refletimos teoricamente sobre corpos, masculinidades e sexualidades não normativas no esporte, bem como apontamos que as obras descentram as noções de virilidade e eficiência atreladas à masculinidade clássica, nos levando à compreender as subversões que os atletas queer provocam nos padrões clássicos de gênero e a demanda de questões que fazem emergir para a organização esportiva contemporânea, bem como para a Educação Física.
\end{abstract}

Palavras-Chave: Esportes. Gênero. Sexualidade. Filmes.

\section{Introdução}

A história do esporte nos mostra que essa manifestação social se constituiu enquanto espaço privilegiado de expressão da masculinidade tradicional. No entanto, nos dias atuais, o esporte dialoga com uma demanda emergente de corpos que subvertem as lógicas da virilidade clássica e dos padrões heterocentrados que dominam hegemonicamente o mundo esportivo desde os seus primórdios. Corroboramos, assim, com o pensamento de Jaeger e Goellner (2011, p.966) ao afirmarem que: "identificamos o esporte como um espaço propício para tencionar as representações de gênero, pois nele produzem-se corpos e subjetividades que desestabilizam as determinações biológicas". Diante disso, as práticas esportivas tem sido palco da expressividade de masculinidades e feminilidades não-tradicionais e diversas, que rompem com as estruturas e modelos unívocos de gênero e sexualidade.

Nessa direção, as sexualidades contra-hegemônicas ao ganharem espaço e visibilidade no âmbito esportivo, geram a necessidade de repensar e redimensionar essas configurações binárias e heterossexistas no esporte, como nos fala Araújo (2012, p.68):

O esporte, não alheio à conjuntura social que o abarca, identifica (mesmo que com resistência) tais questionamentos e/descentramentos em seu campo que possibilitam uma complexificação das posições binárias e maniqueístas em torno do gênero e sexualidade dos sujeitos/atletas. Contudo, destacamos a resistência do fenômeno esportivo a essa nova demanda por compreender 
que esta desestabiliza a prática esportiva, inclusive, em sua clássica forma de organização das modalidades por categoria e gênero (ARAÚJO, 2012, p.68).

É justamente a respeito desse jogo de resistências, subversões e continuidades a respeito dos padrões de gênero e sexualidade no esporte que versam as películas que serão apresentadas e discutidas nesse escrito. E a partir da apreciação das mesmas objetivamos refletir sobre a prática esportiva dos atletas queer e suas implicações para a conjuntura esportiva, bem como para a Educação Física.

O trabalho de cunho interdisciplinar articula, sobretudo, conhecimento da área da comunicação e da Educação Física, além de recorrer a outras disciplinas humanísticas que podem contribuir com as reflexões, tais como: sociologia, antropologia, filosofia, dentre outras. As argumentações se dão a partir da apreciação e pela interpretação de imagens (AUMONT, 1993) que interpela a significação primária ou natural (fato representado e nível expressivo) e a significação secundária ou convencional (atribuição de valor a partir de referência cultural).

No conjunto das análises adotamos como recurso metodológico a descrição da experiência estética das imagens do esporte a partir de quatro conceitos apontados por Gumbrecht (2006), a saber: o conteúdo da experiência, entendido como produções subjetivas desencadeadas a partir da apreciação estética e que podem estar dialogadas com sensações, conceitos e impressões sobre o objeto; os objetos da experiência estética, compreendidos enquanto a materialidade que dialoga com a percepção do sujeito; as condições da experiência estética, percebida enquanto demarcação histórica e social da possibilidade de apreciação e; os efeitos da experiência estética que demandam uma mudança estrutural na compreensão do fenômeno apreciado.

A partir da recorrência dos temas de gênero e sexualidade no ambiente esportivo, principalmente da tematização do corpo queer neste espaço, escolhemos as duas produções em evidência neste trabalho: Guys and Balls (2004) e Summer Storm (2004). Os filmes foram apreciados para identificar as cenas que questionam o espaço do queer na ação esportiva através da descrição da experiência estética supracitada. Foi criada uma ficha de análise, organizada em duas categorias, a primeira intitulada de objetos e condições da experiência estética se divide nas seguintes subcategorias: Foco narrativo; cenário e figurino; trilha sonora; câmera e fotografia, cujos resultados serão apresentados. A segunda categoria de análise diz respeito ao conteúdo e efeitos da experiência estética, subdividida em: corpo e gênero; corpo e sexualidade; esporte e estigma; eficiência e descentramento; corpo e ética. No caso da segunda categoria, seus resultados corroboram mais incisivamente para compreender o sujeito queer que descentra de um gênero tradicional, tal como apresentaremos adiante.

Para este intento, a estrutura de leitura estética sugerida por Gumbrecht (2006) e por nós adaptada a partir da ficha de análise criada por Nóbrega (2011), balizada nas visibilidades do corpo no cinema, possibilitaram a construção do guia de análise abaixo: 


\begin{tabular}{|c|c|c|c|}
\hline \multicolumn{2}{|c|}{ Itens de análise } & Guys and Balls & Summer Storm \\
\hline \multirow{7}{*}{$\begin{array}{l}\text { Dados de } \\
\text { dentificação }\end{array}$} & $\begin{array}{l}\text { Título original e em } \\
\text { Inglês }\end{array}$ & $\begin{array}{l}\text { Männer wie wir/ Guys } \\
\text { and Balls }\end{array}$ & $\begin{array}{c}\text { Sommersturm/ Summer } \\
\text { Storm }\end{array}$ \\
\hline & $\begin{array}{l}\text { Ano e País de Pro- } \\
\text { dução }\end{array}$ & Alemanha/2004 & Alemanha/2004 \\
\hline & Direção & Sherry Hormann & Marco Kreuzpainter \\
\hline & Gênero & $\begin{array}{l}\text { Drama/ Comédia/ Ro- } \\
\text { mance }\end{array}$ & Drama/Romance/Comédia \\
\hline & Duração & 106 minutos & 94 minutos \\
\hline & Idioma & Alemão & Alemão \\
\hline & Suporte & Digital & Digital \\
\hline \multirow{5}{*}{$\begin{array}{l}\text { Objetos e } \\
\text { condições } \\
\text { da experi- } \\
\text { ência estéti- } \\
\text { ca }\end{array}$} & Argumento & $\begin{array}{l}\text { Goleiro expulso de } \\
\text { equipe de futebol por } \\
\text { ser gay }\end{array}$ & $\begin{array}{c}\text { Descoberta da sexualidade } \\
\text { na ambiência esportiva do } \\
\text { remo }\end{array}$ \\
\hline & Foco narrativo & $\begin{array}{c}\text { O narrador é o autor } \\
\text { do filme }\end{array}$ & $\begin{array}{l}\text { O narrador é o autor do } \\
\text { filme }\end{array}$ \\
\hline & Cenário e Figurino & Esportivo & Esportivo \\
\hline & $\begin{array}{l}\text { Trilha sonora/sono- } \\
\text { rização }\end{array}$ & Som em $O f f$ & $\begin{array}{c}\text { Som em Off, trilha sensí- } \\
\text { vel }\end{array}$ \\
\hline & $\begin{array}{l}\text { Fotografia e Câme- } \\
\text { ra }\end{array}$ & $\begin{array}{l}\text { Paisagens iluminadas, } \\
\text { ênfase nos movimen- } \\
\text { tos esportivos do go- } \\
\text { leiro }\end{array}$ & $\begin{array}{c}\text { Iluminação forte, lentidão, } \\
\text { ênfase em plano america- } \\
\text { no }\end{array}$ \\
\hline \multirow{5}{*}{$\begin{array}{l}\text { Conteúdo e } \\
\text { efeitos da } \\
\text { experiência } \\
\text { estética }\end{array}$} & Corpo e gênero & $\begin{array}{c}\text { Descentramento dos } \\
\text { estereótipos }\end{array}$ & Ruptura dos binarismos \\
\hline & $\begin{array}{l}\text { Corpo e sexualida- } \\
\text { de }\end{array}$ & $\begin{array}{c}\text { Explicitação da } \\
\text { sexualidade desviante }\end{array}$ & $\begin{array}{l}\text { Explicitação do desejo ho- } \\
\text { mossexual em algumas ce- } \\
\text { nas }\end{array}$ \\
\hline & Esporte e estigma & $\begin{array}{l}\text { Descontrução do es- } \\
\text { tigma da falta de com- } \\
\text { petência dos jogado- } \\
\text { res gays }\end{array}$ & $\begin{array}{l}\text { Visibilidade gay no espor- } \\
\text { te, presença de estereóti- } \\
\text { pos e estigmas }\end{array}$ \\
\hline & $\begin{array}{l}\text { Eficiência e descen- } \\
\text { tramento }\end{array}$ & $\begin{array}{l}\text { Problematização do } \\
\text { estereótipo do gay } \\
\text { como sujeito frágil no } \\
\text { esporte. }\end{array}$ & $\begin{array}{l}\text { Motra a competência do } \\
\text { esportista gay }\end{array}$ \\
\hline & Corpo e ética & Trapaças & $\begin{array}{c}\text { Discriminação do gay no } \\
\text { esporte }\end{array}$ \\
\hline
\end{tabular}

Os filmes foram utilizados como recurso analógico para pensar estas questões apontadas. Disso deriva a não intenção de fazer análises fílmicas, no rigor que o termo tem se desenhado no formato acadêmico, mas antes uma atitude do olhar interrogante do pesquisador que mais se aproxima de uma análise que considera o texto fílmico no que se refere à representação de gênero e sexualidade no cinema, bem como o contexto da produção da obra, sendo o filme um testemunho artístico da compreensão do esporte. 
A partir dos pontos elencados em cada ficha de análise, foram agrupadas as recorrências de sentido em cada subcategoria, ou seja, o que foi percebido de comum entre os dois filmes, bem como as representações destoantes para que fossem organizados os resultados da pesquisa.

\section{Queerizando o esporte: estigmas, subversões e resistências}

Antes de mergulharmos no universo dos filmes Summer Storm (2004) e Guys and Balls (2004), é preciso nos deixar tomar pelo universo fascinante do queer e de seus atletas que se fazem presentes nos filmes e nos fazem refletir sobre corpo, gênero e sexualidade no mundo esportivo. Queer, de acordo com Camargo e Rial (2009) é uma designação insubmissa, subversiva e desafiadora que abrange todos os arranjos concernentes à população LGBT (gays, lésbicas, travestis, bissexuais, transgêneros), cuja existência e investigação somente é possível pelas transformações sociais sofridas nas últimas décadas do século XX com os movimentos feministas, de gays e lésbicas. Nessa direção, Louro (2013), nos brinda com a seguinte definição de queer:

Queer é tudo isso: é estranho, raro, esquisito, queer é, também, o sujeito da sexualidade desviante - homossexuais, bissexuais, transexuais, travestis, Drags. É o excêntrico que não deseja ser "integrado" e muito menos "tolerado". Queer é um jeito de pensar e de ser que não aspira o centro nem o quer como referência, um jeito de pensar que desafia as normas regulatórias da sociedade, que assume o desconforto da ambiguidade, do "entre lugares", do indecidível. Queer é um corpo estranho, que incomoda, perturba, provoca e fascina (LOURO, 2013, p.7,8).

Esses corpos queer sobre os quais nos fala a autora supracitada, ao expressarem dissonâncias com os paradigmas instituídos de gênero no esporte, pertubam as normas instituídas, criando uma nova subjetividade esportiva e estilística corporal diametralmente oposta a matriz heteronormativa dominante, e acabam por queerizar/subverter as lógicas desses ambientes esportivos por onde passam, negando qualquer tentativa classificatória ou rótulo.

Nessa direção, a própria teoria queer é subversiva assim como os sujeitos de que fala, ao questionar os binarismos hétero-homo, masculino-feminino, deseja romper com uma política de identidade fixa que classifica os corpos de forma reducionista. No entanto, o movimento queer não tem um caráter apaziguador que almeja incluir os sujeitos divergentes da norma, o queer prefere o conflito, a divergência e o questionamento das próprias normas e convenções que regram a existência corporal e sexual, bem como seus processos de construção. O principal alvo queer, segundo Miskolci (2012) é a heterormatividade, entendida como a "ordem sexual do presente, fundada no modelo heterossexual, familiar e reprodutivo. Ela se impõe por meio de violências simbólicas e físicas dirigidas principalmente a quem rompe normas de gênero"(MISKOLCI, 2012, p.43,44).

Ao realizar essas problematizações, o queer chama a atenção para a pluralização de corpos, desejos, arranjos sexuais que desmantelam o modelo instituído e construído social e culturalmente, mostra que a heteronormatividade não é a única forma legítima de viver a sexualidade e que o corpo não cabe em formas unívocas e determinadas de identidade. A teoria queer ao colocar em cena esses corpos diferentes e antinormalizadores corrobora com o pensamento de Butler (2013) ao apontar que o processo de materialização das normas no 
corpo é sempre incompleta porque "[...] os corpos não se conformam, nunca, completamente, às normas pelas quais sua materialização é imposta”(BUTLER, 2013, p.154).

Ao nos reportarmos à representação fílmica desses corpos queer no mundo esportivo, destacamos as películas alemãs Guys and Balls e Summer Storm postas em tela neste estudo, enquanto registros que nos levam a refletir sobre esse cenário ao versarem sobre equipes esportivas compostas por atletas queer. O termo queer aparece em ambos os filmes para designar os sujeitos descentrados da sexualidade heteronormativa, e no segundo, além disso, representa o nome de uma das equipes partícipes do campeonato de remo como forma de explicitação e afirmação da sexualidade não normativa de seus componentes. Os filmes datam do ano de 2004, e tem em comum, dentre outras coisas, a narrativa de sujeitos descentrados da sexualidade dominante, que expressam uma subjetividade queer no esporte e sofrem estigmas nesse cenário ou em equipes majoritariamente heteronormativas, ao mesmo tempo em que se confrontam com a formação de nichos esportivos gays.

Summer Storm conta a história de Tobi, atleta e capitão de sua equipe de remo que vive a confusão de descobrir-se homossexual ao mesmo tempo em que participa de um campeonato, no qual uma das equipes é completamente queer, fato que reverbera nos rumos da vida de Tobi e do próprio campeonato. Por sua vez, Guys and Balls, narra a história de Ecki, goleiro de uma equipe de futebol de uma cidade pequena, que é expulso do time pelos demais jogadores ao descobrirem que ele é gay. A partir desse momento, o goleiro sai à procura de outros jogadores homossexuais no intuito de formar uma equipe totalmente queer e duelar simbólica e praticamente contra os heterossexuais ou contra a heteronormatização do esporte, em específico, do futebol.

As duas produções trazem como personagens principais, homens que estão se descobrindo homossexuais na ambiência esportiva, e que ao explicitar a sexualidade nesse contexto sofrem preconceito e afastamentos desse universo, como se este espaço não os pertencesse. Este fato pode ser visualizado nas narrativas a partir de discursos e cenas representativas de preconceito para com esses sujeitos. Esse quadro é levemente maximizado em Guys and Balls, talvez pelo fato da película mostrar o sujeito gay no futebol, prática sacralizada da expressão da masculinidade e virilidade clássicas.

Nessa produção, o futebol é reificado enquanto fortaleza do atleta homem, heterossexual e másculo, e a expressão máxima dessa relação entre futebol e masculinidade clássica acontece com a expulsão de Ecki da equipe heterocentrada pelo fato do personagem ser homossexual, e pode ser visualizada nos discursos dos demais jogadores, que disparam: "Futebol é guerra! E somente homens podem ir para a guerra"; "Encontre você mesmo um time homo se você quiser jogar[...] homos não podem jogar futebol[...]tem a ver com os genes."; “Agora eu entendo! Nós temos um goleiro queer..que homo fedorento!". Tais discursos confirmam o futebol enquanto esporte heterocentrado e generificado para o masculino, e confirmam, como nos fala Rojo e Melo (2006) que o mundo esportivo é um espaço dividido por gênero em sua forma clássica, fato esse que reverbera na produção de um conjunto de preconceitos direcionados contra atletas gays.

Por sua vez, em Summer Storm, a explicitação da sexualidade "desviante" do capitão da equipe majoritariamente heterossexual de remo causa reações preconceituosas, de forma que o fato de ser gay se sobrepõe a figura de capitão do personagem, gerando a segregação do mesmo como se este já não mais pertencesse ao grupo e tivesse perdido seu lugar e poder de capitão.

Esses afastamentos, expulsões e segregações em ambos os filmes nos levam a pensar na formação de grupos e equipes totalmente queers enquanto saída encontrada pelos sujeitos 
para afirmarem uma sexualidade não normativa em um ambiente esportivo não propício, e enquanto forma de confronto e resistência para com os grupos heterocentrados e majoritários. Ao visualizarmos esse fato nas duas produções, percebemos que em Summer Storm já existe uma equipe totalmente queer no cenário do campoenato de remo, enquanto em Guys and Balls, a formação da equipe queer acontece no decorrer da película a partir da expulsão do goleiro gay da equipe heterocentrada.

Ao versar sobre essas atitudes de resistência queer, Camargo (2008) em sua resenha intitulada "Sexualidades, Esportes e Teoria Queer: Inter-relações" salienta a dificuldade encontrada por esses grupos subversivos na tentativa de desafiar as normas heterossexuais impregnadas nas práticas esportivas, apontando a formação de clubes e/ou grupos compostos por minorias sexuais como uma investida para criar um "porto seguro", isento dos signos heteronormativos. Nesse sentido, ao criar essa forma de seguridade, esse sujeitos queer acabam, segundo o autor supracitado, por desobedecer e subverter as lógicas de dominação heterossexual postas de forma visível ou invisível, conquistando a marcação de um território que não os pertence cultural e historicamente.

Os sujeitos descentrados nos filmes confirmam essa utilização dos grupos predominantemente queers no esporte como forma de subversão do predomínio heterocentrado. Guys and Balls e Summer Storm, ao evidenciarem a formação e participação de equipes majoritariamente gays ou queers no esporte, mostram os árduos enfrentamentos desses grupos subversivos como forma de resistir à masculinidade hegemônica e afirmar-se de forma coletiva e segura no espaço esportivo marcadamente heterossexual.

\section{Estigmas do corpo masculino não tradicional no esporte: eficiência e virilidade}

Ao centrarmos nossa atenção na noção de eficiência esportiva para pensar os estigmas atrelados aos corpos masculinos desviantes na sexualidade e/ou no gênero (corpos queer), percebemos que os estigmas direcionados para eles estão associados às lógicas da virilidade e masculinidade clássicas como únicas formas possíveis de ser viril e eficiente no esporte. Nesse sentido, Tamagne (2013) afirma que o homossexual ainda é visto como o sujeito que falhou em sua virilidade, ou seja, o sujeito que não é másculo ou suficientemente viril para o mundo esportivo, sendo desacreditado.

Nessa direção, os sujeitos que não afirmam em seu corpo os códigos da masculinidade tradicional, possuindo algumas marcações ou signos do universo feminino, sejam de ordem física ou simbólica, ou ainda que afirmem a homossexualidade no mundo esportivo como os personagens das películas analisadas, são alvos de inferiorização e subestima quanto ao seu rendimento e eficiência nos esportes. Em Guys and Balls, por exemplo, são evidentes discursos expostos pelo time heterossexual que enfantizam os sujeitos gays como incapazes de jogar ou como inferiores, como podemos observar na seguinte frase da cena que antecede a partida e o duelo final entre héteros e homos: "Nós vamos mostrar a esses queers como se joga futebol". Essa fala evidencia a ligação entre uma aparência descentrada ou sexualidade desviante a uma possível falta de habilidade, força e competência esportiva, bem como remete a uma suposta superioridade heterossexual.

No entanto, ao mesmo tempo em que retratam os estigmas fortes e enraizados para com o gay no esporte e as inúmeras tentativas de afastar os personagens descentrados do gênero e da sexualidade das equipes e competições, os filmes tentam desconstruir os estereótipos e estigmas do homossexual no esporte. Nesse sentido, mostram que a competência dos sujeitos independe dos indicadores culturais de afirmação da sexualidade, proble- 
matizando o estereótipo do gay como sujeito frágil, "afeminado" e incompetente no esporte, principalmente através da validação da habilidade, virilidade e competência esportiva dos sujeitos gays, que vencem simbolicamente o duelo contra os heterossexuais, ao ganhar o jogo e a regata que finalizam os filmes. Tal competência que culmina nas vitórias dos queers, está atrelada à performances esportivas balizadas na força e na virilidade, distanciando-se da representação do homossexual como "afeminado", ineficiente e não viril.

No caso de Summer Storm, especialmente, existe uma ruptura da expectativa corporal do gay como sujeito "afeminado", tendo em vista que a equipe queer é composta por homens que apresentam, em sua maioria, principalmente na figura do capitão Walter (imagem 1 abaixo), uma arquitetura corporal musculosa, sem trejeitos próximos do feminino, descentrando as marcações esperadas para o sujeito queer no esporte, como é possível obervar nas imagens abaixo:
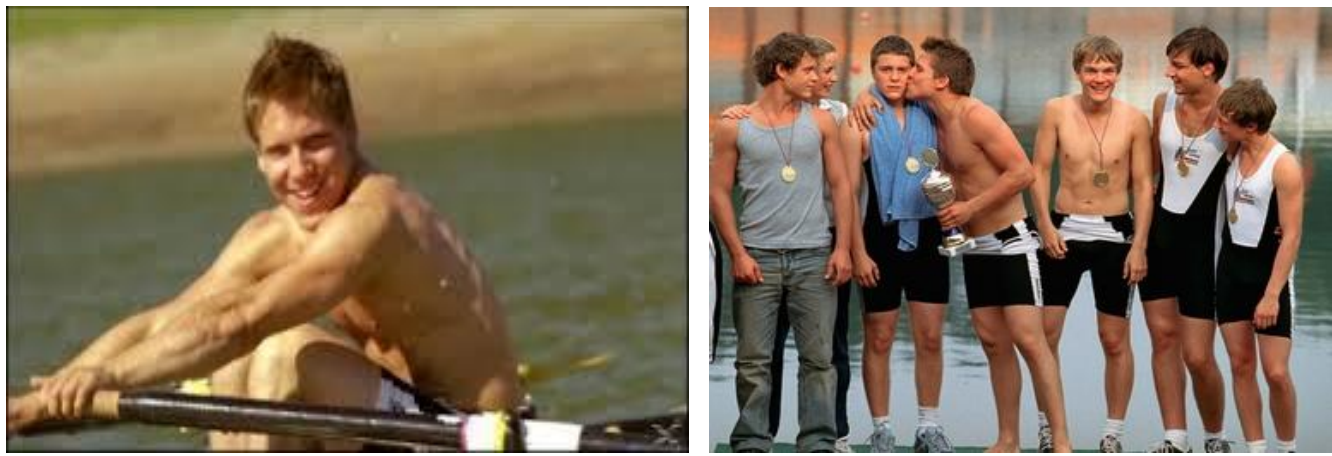

Imagens 1 e 2 - Descentramentos queer no esporte: Músculos e virilidades homossexuais em Summer Storm Fonte: Cenas do filme Summer Storm (Marco Kreuzpaintner, 2004)

No caso de Guys and Balls esse descentramento também é evidente, principalmente na figura do personagem principal gay (Ecki), que não afirma em seu corpo masculino signos e condutas culturalmente atreladas ao universo feminino. No entanto, é interessante destacar que nesta película existe uma maior caricaturização do feminino e diversidade de masculinidades de alguns personagens gays que formam a equipe de futebol queer por meio do figurino e da gestualidade, como podemos visualizar na imagem:

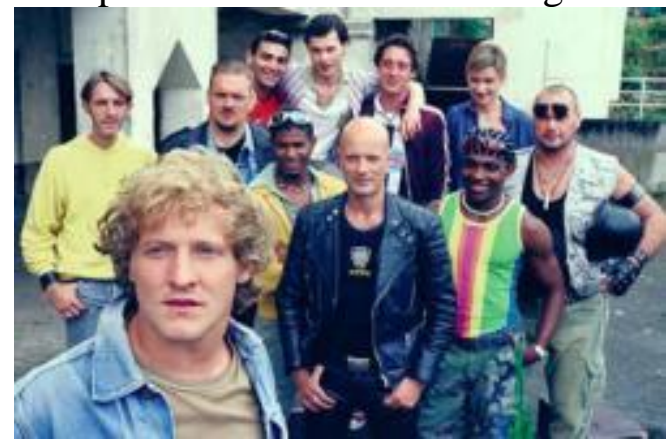

Imagem 3: Masculinidades no futebol

Fonte: Cenas do filme Guys and Balls (Sherry Hormann, 2004)

O personagem principal (goleiro Ecki), em evidência na imagem acima, descentra o esteriótipo feminilizado e frágil, tem um corpo musculoso, usa vestimentas tradicionais masculinas, não afirma códigos femininos em seu corpo e tem habilidade considerável no futebol, prática que lhe acompanha desde criança. Ao tentar montar seu time gay, Ecki se 
depara com figuras diferentes, às vezes caricaturadas, desde o gay "afeminado", passando pelo gay que finge ser hétero para os amigos. No entanto, todos fogem do estereótipo de ineficiência e demonstram habilidade e competência esportiva independente de uma estilística corporal próxima do feminino, ou da afirmação de trejeitos e expressividades distantes do masculino tradicional, de forma que a performance gay no esporte equipara-se à performance técnica dos sujeitos que afirmam uma sexualidade normativa. Essas performances ajudam a redefinir os parâmetros de uma virilidade homossexual, ao mesmo tempo em que subvertem as noções definidas do que é ser masculino nos seus moldes tradicionais. Os gays rompem com o modelo viril heterossexual, instaurando sua virilidade singular, sem deixar de sê-lo (TAMAGNE, 2013).

As histórias desses sujeitos esportistas que publicizam sua sexualidade não normativa apresentam em comum narrativas de:

[...] Atletas que tiveram, em maior ou menor escala, seu estatuto de atleta questionado por expressar uma sexualidade distinta da heterossexual. Atletas que foram chacoteados no princípio da carreira e que, ao se afirmarem competentes no enredo principal do mundo esportivo [...] conseguem tolerância no campo de competição (ARAÚJO, 2012, p.85).

A recorrência crescente de atletas que assumem sua homossexualidade nos mostra uma determinada "tolerância" conquistada pelos atletas queer pela sua "simples" presença no cenário esportivo profissional, colaborando para romper a relação linear, produzida historicamente, entre o esporte, a virilidade e a masculinidade tradicional. No entanto, as narrativas, tanto fílimicas quanto da realidade atual, registram que esse processo não é harmonioso tendo em vista a forte resistência que ainda existe no âmbito esportivo a essas atitudes e discussões. Essa resistência, como percebemos nas películas, são materializadas por vezes em gestos, discursos e ações preconceituosas e estigmatizantes para com os atletas gays.

\section{Considerações finais}

Após as apreciações e análises das fichas, apontamos que as obras descentram as noções de virilidade e eficiência atreladas à masculinidade clássica ao visibilizar gays viris e eficientes no esporte com performances vitoriosas, contrariando as crenças e expectativas pessimistas quanto a eficácia dos homossexuais no cenário esportivo. Para além desse descentramento, as produções concedem espaço e visibilidade central às questões de afirmação da sexualidade e de formação de grupos de atletas queer, enquanto movimento de resistência dos gays, que lutam por respeito e pelo acesso às práticas esportivizadas. $\mathrm{E}$ ao possibilitarem essa visibilidade, contribuem de forma emblemática para pensar e discutir a presença desses sujeitos no âmbito esportivo, compreendendo as subversões que provocam nos padrões clássicos de gênero e a demanda que fazem emergir para a organização esportiva contemporânea, sendo de indispensável consulta para aqueles que se atraem pela designação queer no esporte. As películas também mostram os estigmas enfrentados por esses sujeitos e os obstáculos que enfrentam ao romperem com o gênero e a sexualidade tradicionais.

Ao pensarmos na explicitação da sexualidade "desviante" no contexto esportivo mundial real da atualidade e suas consequências, vamos encontrar inúmeras histórias que se assemelham às realidades fílmicas apresentadas no tocante aos sujeitos descentrados do gênero e da sexualidade, que se fazem presentes nos diversos espaços da cultura esportiva, bem como aos estigmas sofridos por estes, os enfrentamentos e rupturas que proporcionam. 
No entanto, algumas práticas tem tido maior destaque neste processo de descentramento, tal como o voleibol, mas não somente ele, podendo-se citar também o futebol e o rugby, estes últimos considerados como fortalezas da masculinidade normatizada e heterocentrada.

Nesse sentido, apreciar as películas colocadas em tela neste estudo, significa entrar em contato com um universo esportivo contemporâneo que é refletido para além das cenas e se estende à realidade; um mundo queer, subversivo e fascinante, cujos duelos estão para além das competições reais esportivas entre homens e mulheres. Seus jogos esportivos, simbólicos e de gênero abarcam a desconstrução de cânones impregnados na cultura e nos ajudam a refletir sobre a emergência de corpos, sexualidades, masculinidades e feminilidades que se apresentam no cenário esportivo com novas subjetividades e proposições estéticas e políticas.

Os filmes explorados ajudam a refletir sobre a prática esportiva dos atletas, inclusive os queer, que atuam de forma tensional entre a normatividade de uma prática corporal e a expressividade de sua sexualidade (em amplo sentido). A implicação para a conjuntura esportiva reside no questionamento da capacidade da instituição esportiva comportar a todos, com respeito às diferentes formas de ser. Essa questão deve ser refletida também no âmbito da Educação Física, enquanto área que tematiza o esporte e a expressividade em diversas outras práticas corporais.

Ao finalizar este ensaio, registra-se que tais reflexões são de extrema necessidade para o campo acadêmico e de prática da Educação Física, que parece estar distante destas questões latentes na conjuntura esportiva. Nesse sentido, ao questionarmos a presença do queer na Educação Física nos deparamos com alguns estudos que tematizam a relação gênero/esporte, em sua maioria, tematizando a generificação das práticas corporais e esportivas, mas que não se aprofundam nos estigmas relativos à sexualidades não normativas.

Assistimos também inúmeras práticas discriminatórias para com homossexuais nos mais diversos campos de atuação, seja na escola, nos clubes ou equipes esportivas. Nesse sentido, a Educação Física e seus profisisonais não podem se eximir de suas responsabilidades, atentando para essas questões e não contribuindo para o reforço da generificação e dos preconceitos, que culminam no escanteamento dos gays para espaços guetificados no âmbito das práticas corporais.

Diante dessas problematizações, registramos que essas discussões precisam alcançar cada vez mais o âmbito acadêmico e formativo dos profissionais de Educação Física, contribuindo para romper com os dualismos, categorizações, classificações, tradicionalismos que regem a prática esportiva e corporal dos sujeitos queer. Para concretizar esses anseios, talvez um dos caminhos consista na incorporação de um currículo e de uma prática pedagógica provocadora e subversiva que se assemelhe aos corpos queer, que não se conformem ao tradicionalismo e não permaneçam no lugar onde os ditames sociais desejam, mas que transitem nos espaços estruturais e discursivos, rompendo com os dualismos e estigmas enraizados nesses âmbitos.

No caso da Educação Física é preciso que estas questões sejam colocadas efetivamente no âmbito da formação inicial dos professores, para que estes possam, a partir de um olhar crítico e consciente, problematizar a generificação das práticas corporais em seus espaços de atuação. Essa atitude constitui-se em uma tentativa de minar os preconceitos com aqueles corpos que afirmam características de sexualidades não-normativas, não permanecendo no conformismo e atravessando os muros e fronteiras que tentam dicotomizar e classificar os seres humanos, que possuem a característica inconfundível de serem únicos em sua forma de existir corporalmente. 


\title{
QUEER RESISTANCE: MARKING GAY TERRITORY IN THE HETERONORMATIVE SCENE OF SPORT
}

\begin{abstract}
This study aims to reflect about the queer athletes on the sports and their implications for modern sports conjuncture, as well as physical education. we analyzed two films: Summer Storm (2004) and Guys and Balls (2004) who put in long with this queer universe in sports. From the examination of the productions, we reflect theoretically about bodies, masculinities and non-normative sexualities in sport, concluding that this films decenter notions of manliness, efficiency and masculinity classical, making us understand the subversions that queer athletes cause in the patterns classical genre and the demand of issues that are emerging in contemporary sports organization, as well as physical education.
\end{abstract}

Keywords: Sport. Gender. Sexuality. Films.

\section{RESISTENCIA QUEER: MARCAR EL TERRITORIO GAY EN EL DEPORTE HETERO- NORMATIVO}

Resumen:Este estudio tiene como objetivo reflexionar sobre los atletas queer en los deportes y sus consecuencias para la coyuntura deportiva moderna, así como para la educación física. Para esto se analizaron dos películas: Tormenta de verano (2004) y Los chicos y Pelotas (2004) que puso en largo con este universo queer en el deporte. A partir del análisis de las producciones pensamos teóricamente sobre las masculinidades y las sexualidades no normativas en los deportes y apuntamos que las obras descentran nociones de masculinidad ligada a la eficiencia clásica, que nos lleva a comprender las subversiones que causan estos atletas en los patrones clásicos y la demanda de cuestiones de género que están surgiendo en la organización deportiva contemporánea, así como en la educación física.

Palabras-clave: Deportes. Género. Sexualidad. Películas.

\section{Referências}

ARAÚJO, A. C. Elementos do pós moderno na representação do esporte no cinema contemporâneo. 2012. 153 f. Tese (Doutorado em Comunicação)- UFPE, Recife, 2012.

AUMONT, Jacques. A imagem. Campinas, Papirus, 1993.

CAMARGO, W. X. Sexualidades, esportes e Teoria Queer: inter-relações. Estudos Feministas, Florianópolis, v.16, n.3, p.1130-1133, 2008.

BUTLER, J. Corpos que pesam: sobre os limites discursivos do "sexo". In:LOURO, G, L. (Org.). O corpo educado: pedagogias da sexualidade. Belo Horizonte: Autêntica, 2013.

CAMARGO, Wagner Xavier. RIAL, Carmem Silva de M. Esporte LGBT e Condição PósModerna: notas antropológicas. Cad. de Pesq. Interdisc. em Ciências Humanas, Florianópolis, v.10, n.97, p. 269-286, jul, 2009.

GUMBRECHT, H. U. Pequenas crises: experiência estética nos mundos cotidianos. In: GUIMARÃES, Cesar; LEAL, Bruno Souza; MENDONÇA, Carlos Camargos (Orgs.). Comunicação e Experiência estética. Belo Horizonte: Editora da UFMG, 2006.

JAEGER, A; GOELLNER, S.V. O músculo estraga a mulher? A produção de feminilidades no fisiculturismo. Estudos Feministas, Florianópolis, v.19, n.3 p. 955-975, set-dez/2011. 
LOURO, Guacira Lopes. Um corpo estranho: Ensaios sobre sexualidade e teoria queer. 2.ed.Belo Horizonte: Autêntica Editora, 2013.

MISKOLCI, R. Teoria Queer: um aprendizado pelas diferenças. Belo Horizonte: Autêntica, 2012.

NÓBREGA, T. P. Visibilidades do Corpo e da Cultura de Movimento Urbana (Relatório de Pesquisa). 2011.

ROJO, L. F.; MELO, V.A. As Damas de Ferro - Comentário do Filme. Esporte e Sociedade, Rio de Janeiro, v. n.2, p.1-5, 2006.

TAMAGNE, Florence. Mutações homossexuais. In: COURTINE, Jean-Jacques (Orgs.). História da virilidade: A virilidade em crise? Séculos XX-XXI. Petrópolis, RJ: Vozes, 2013, v.3.

Recebido em: 08/11/2014

Revisado em: $12 / 02 / 2015$

Aprovado em: 26/02/2015

Endereço para correspondência:

paulinha_nunes3@hotmail.com

Paula Nunes Chaves

Universidade Federal do Rio Grande do Norte, Centro de Ciências da Saúde, Departamento de

Educação Física.

Campus Universitário, s/n - Departamento de Educação Física

Lagoa Nova

59072970 - Natal, RN - Brasil 